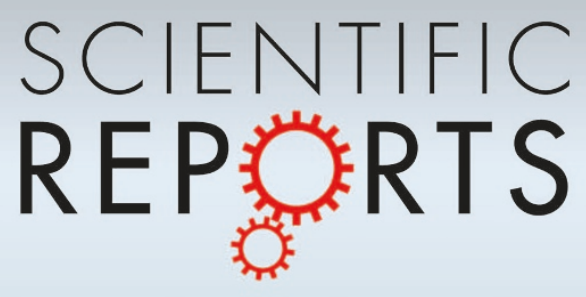

OPEN

SUBJECT AREAS:

ENVIRONMENTAL

SCIENCES

ENVIRONMENTAL CHEMISTRY

Received

31 December 2013

Accepted

27 June 2014

Published

14 July 2014

Correspondence and requests for materials should be addressed to R.Q.L. (liu.603@osu. edu)

\section{Synthetic apatite nanoparticles as a phosphorus fertilizer for soybean (Glycine max)}

\author{
Ruiqiang Liu \& Rattan Lal
}

Carbon Management \& Sequestration Center, School of Environment \& Natural Resources, the Ohio State University, 210 Kottman Hall, 2021 Coffey Road, Columbus, Ohio 43210, USA.

Some soluble phosphate salts, heavily used in agriculture as highly effective phosphorus (P) fertilizers, cause surface water eutrophication, while solid phosphates are less effective in supplying the nutrient $P$. In contrast, synthetic apatite nanoparticles could hypothetically supply sufficient $P$ nutrients to crops but with less mobility in the environment and with less bioavailable $P$ to algae in comparison to the soluble counterparts. Thus, a greenhouse experiment was conducted to assess the fertilizing effect of synthetic apatite nanoparticles on soybean (Glycine max). The particles, prepared using one-step wet chemical method, were spherical in shape with diameters of $15.8 \pm 7.4 \mathrm{~nm}$ and the chemical composition was pure hydroxyapatite. The data show that application of the nanoparticles increased the growth rate and seed yield by $32.6 \%$ and $20.4 \%$, respectively, compared to those of soybeans treated with a regular P fertilizer $\left(\mathrm{Ca}\left(\mathrm{H}_{2} \mathrm{PO}_{4}\right)_{2}\right)$. Biomass productions were enhanced by $18.2 \%$ (above-ground) and $41.2 \%$ (below-ground). Using apatite nanoparticles as a new class of $\mathrm{P}$ fertilizer can potentially enhance agronomical yield and reduce risks of water eutrophication.

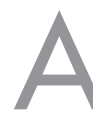

griculture is the major user of mined phosphorus $(\mathrm{P})$, accounting for $80-90 \%$ of the world demand for $\mathrm{P}^{1}$. Increasing population, growing preferences towards meat-based diets, and rising demands for bio-energy crops will increase the future demand for $\mathrm{P}$ fertilizers ${ }^{1}$. However, application of $\mathrm{P}$ fertilizers exacerbates eutrophication problem in surface waters $^{2-6}$. Thus, numerous regulations, best managements practices $(\mathrm{BMPs})^{8-10}$, and remediation technology ${ }^{11,12}$ have been proposed to reduce $\mathrm{P}$ fertilizer application and to prevent the applied $\mathrm{P}$ from entering water bodies. Whereas, there are few if any reports on attempting to solve the eutrophication problem through modifications of the chemical properties of a $\mathrm{P}$ fertilizer (e.g., reducing the $\mathrm{P}$ mobility in the soil or decreasing bioavailability of $\mathrm{P}$ to the algae) so that the modified $\mathrm{P}$ fertilizers are not only as effective as the conventional ones but also have minimal risks of eutrophication. To this end, we hypothesized that use of $\mathrm{P}$ nanoparticle fertilizer, as an alternative to the regular P fertilizers on agricultural lands, would enhance agronomic production, use efficiency of $\mathrm{P}$, and improve the surface-water quality.

Generally, commercially available $\mathrm{P}$ fertilizers such as MAP (monoammonium phosphate, $\mathrm{NH}_{3} \mathrm{H}_{2} \mathrm{PO}_{4}$ ), DAP (diammonium phosphate, $\left(\mathrm{NH}_{3}\right)_{2} \mathrm{HPO}_{4}$ ), or TSP (Triple Superphosphate, $\mathrm{Ca}\left(\mathrm{H}_{2} \mathrm{PO}_{4}\right)_{2}$ ) are water soluble phosphate salts, which are easily dissolved in the soil solution and available for plant uptake, and thus, are regarded as high quality fertilizers ${ }^{13}$. However, these soluble phosphates are also very mobile in the soil and large portion often ends up in surface-water bodies through runoff or seepage, causing eutrophication. On the other hand, solid forms of $\mathrm{P}$ (e.g., a variety of naturally-occurring phosphate rocks, apatites, $\mathrm{Ca}_{5}\left(\mathrm{PO}_{4}\right)_{3} \mathrm{X}, \mathrm{X}=\mathrm{F}, \mathrm{Cl}, \mathrm{Br}$, or $\mathrm{OH}$ ) have also been attempted as $\mathrm{P}$ fertilizers ${ }^{13}$ where the phosphate is locked in a solid form and is less easily available to the alga and also less easily being transported by runoff or soil erosion. However, these solids are less effective in providing nutrient $\mathrm{P}$ at the critical time (when the plants are in need) ${ }^{13}$. In addition, application of solid phosphates in agriculture is hindered by the large size of the particles, which limits phosphate mobility in the soil and thus prevents phosphate from reaching the root zone and nurturing the crops in a timely fashion. In light of these problems related to the conventional $\mathrm{P}$ application, the nano-sized apatite particles could be as effective in providing the nutrient $\mathrm{P}$ as the commonly-used soluble $\mathrm{P}$ fertilizers while minimizing the secondary contamination risks (e.g., eutrophication) and the delivery problem associated with the latter. The schematics in Fig. 1 present a hypothetic comparison of soluble $\mathrm{P}$, nano-sized solid $\mathrm{P}$, and regular solid $\mathrm{P}$ in the fertilizer effectiveness and eutrophication risk, suggesting that application of nano-sized solid P as fertilizer would be a good compromise between agricultural benefits and the environmental hazards. Specifically, a P nanoparticle suspension, 


\begin{tabular}{ll}
\hline Particle Size & \\
\hline $\begin{array}{l}\text { Mobility in } \\
\text { Soil }\end{array}$ \\
\hline $\begin{array}{l}\text { Fertilizing } \\
\text { Effectiveness }\end{array}$ \\
\hline $\begin{array}{l}\text { Eutrophication } \\
\text { Risk }\end{array}$ \\
\hline
\end{tabular}

Figure $1 \mid$ A schematic comparison of soluble $\mathrm{P}$, nano-sized solid $\mathrm{P}$, and solid $\mathrm{P}$ on their environmental properties (note: some of nanoparticle properties are hypothetical).

characterized by possessing the same mobility in soil columns as an aqueous solution due to nano-scaled particle size, is easily delivered to the root zones with conventional methods (e.g., spray or irrigation). Moreover, the nanoparticles are environmentally benign because the $\mathrm{P}$ in solid form is much less bioavailable to the algae than those in soluble forms ${ }^{14}$. Algae-bioavailable $\mathrm{P}$ is primarily responsible for the eutrophication in fresh surface-waters ${ }^{1-6}$.

Thus, the specific tasks of this report encompass synthesis and characterization of the apatite nanoparticles in carboxymethyl cellulose (CMC) solution, and assessment of the fertilizing (plant nutritional) effect of the particles on soybean yield though a greenhouse study. Examination and confirmation of the nanoparticle's non-toxic property through germination test could be found as the supplementary online material (SOM-1). The environmental impact assessment of the nanoparticles on eutrophication will be reported in another article.

Synthetic nano-sized hydroxyapatite (nHA) characterization. The CMC-stabilized apatite nanoparticles exhibited a light-milky colored suspension which was transparent and could maintain for a few months without significant precipitation (Fig. 2, right). In contrast, the reaction product without $\mathrm{CMC}$ involvement precipitated within a few minutes (Fig. 2, left). A soil-column test indicated that the apatite nanoparticles could pass through the soil column and mix with the soil resembling a solution but the regular apatite particles (without CMC) were retained on the column surface, suggesting that the nano-sized apatite had better mobility in soils than the regular apatite granular and thus more advantageous on delivering nutrient $\mathrm{P}$ to the crops' root system. Fig. 3 presents a TEM micrograph of the apatite nanoparticles. As is evident in this figure, the nanoparticles appeared spherical in shape. There was a variety of particle sizes, with diameters spanning from $\sim 10 \mathrm{~nm}$ to $40 \mathrm{~nm}$ and with an average of $15.8 \pm 7.4 \mathrm{~nm}$ (standard deviation, $\mathrm{N}=300$ ). The X-ray diffractogram (Fig. 4) indicates that hydroxyapatite (HA, PDF No. 01-074-9761) was the major mineral phase of the product synthesized with or without CMC addition. The presence of the amorphous component, CMC, did not significantly affect the XRD peak locations, suggesting that CMC macromolecules produced no drastic changes in the structure of the apatite and that the interactions were so weak that there were no new products formed. A closer comparison of these two XRD patterns (Fig. 4) suggests that there was a small fraction of brushite $\left(\mathrm{CaHPO}_{4} \cdot 2 \mathrm{H}_{2} \mathrm{O}\right.$, PDF No. 01072-0713) impurity ( $\mathrm{d}=7.62 \mathrm{~nm})$ in HA produced without CMC involvement. But the peak representing the impurity $(\mathrm{d}=7.62 \mathrm{~nm})$ disappeared in the nHA-CMC composites, showing that CMC addition increased the purity of HA mineral phase. Additionally, compared to those of HA, all XRD peaks of nHA-CMC composite appeared at slightly smaller $2 \theta$ (i.e., Fig. 4 shows that XRD peaks of nHA-CMC appeared slightly earlier than those of the HA-only counterpart), suggesting that CMC involvement expanded the $\mathrm{d}$ spacing of the synthesized nHA.

Dry combustion of CMC and CMC-nHA composite showed that they contained $33.1 \%$ and $11.6 \%$ of carbon (C) by weight, respectively. Considering that $\mathrm{CMC}$ was the only $\mathrm{C}$ source in the CMC-nHA composite, the CMC content in the composite was $32 \%$ (as CMC by

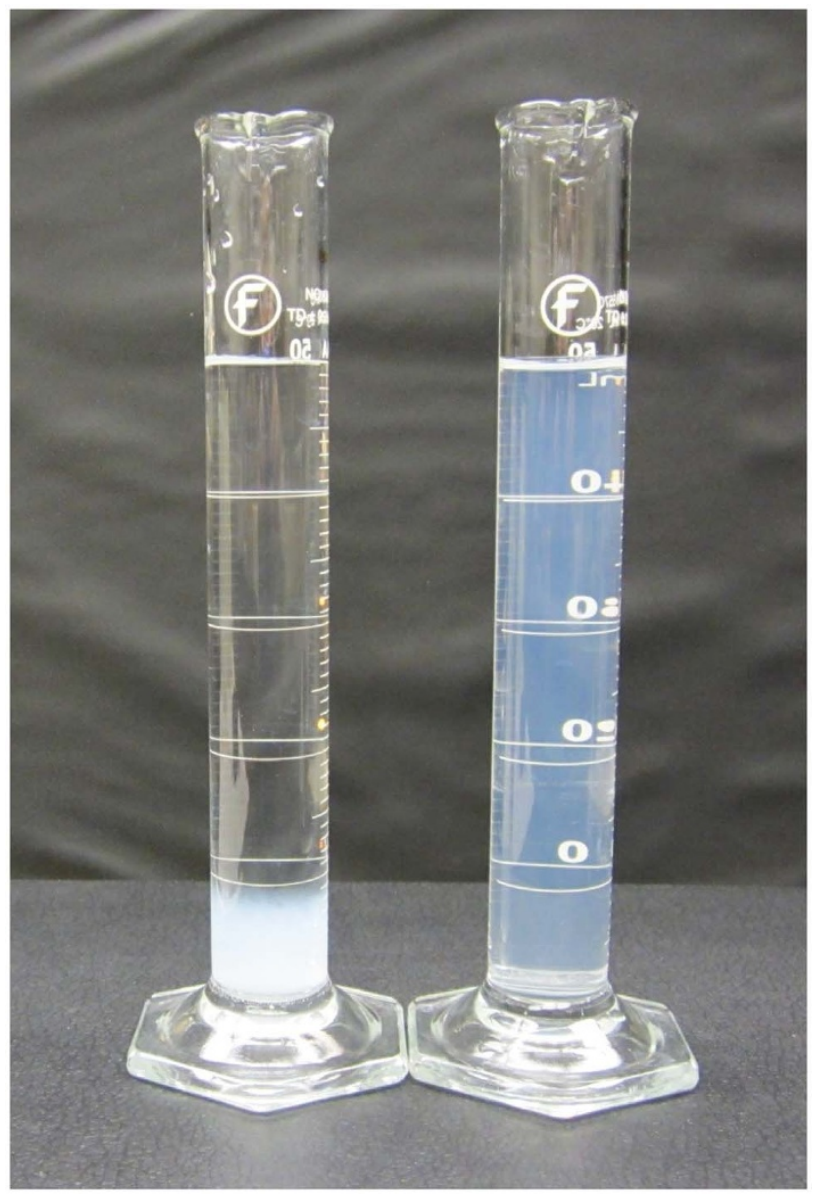

Figure $2 \mid$ Freshly prepared apatite nanoparticle suspensions in the absence of CMC (left) and in the presence of CMC (right). 


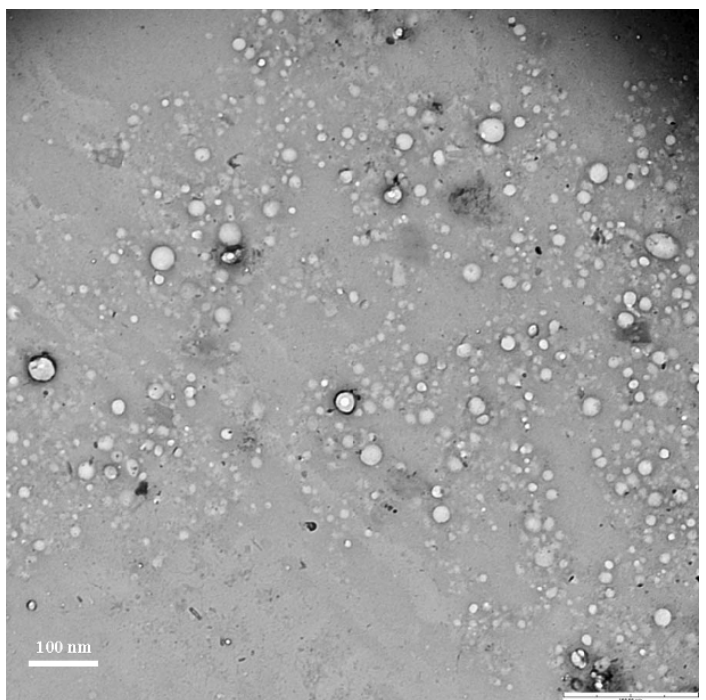

Figure $3 \mid$ A TEM image of nano-sized hydroxyapatite (nHA).

weight) through the measured $\mathrm{C}$ content. Thus, $\mathrm{CMC}$ accounted for about one third of the composite by weight. Assuming the CMC salt has an ideal formula of $\left[\mathrm{C}_{6} \mathrm{H}_{7} \mathrm{O}_{2}(\mathrm{OH})_{2} \mathrm{OCH}_{2} \mathrm{COO} \mathrm{Na}\right]_{n}$, the theoretical C content in the salt is $39 \%$ which is close to the experimentally determined value of $33.1 \%$. Similarly, assuming the nHA with a composition of $\left[\mathrm{C}_{6} \mathrm{H}_{7} \mathrm{O}_{2}(\mathrm{OH})_{2} \mathrm{OCH}_{2} \mathrm{COOCa}_{5}\left(\mathrm{PO}_{4}\right)_{3} \mathrm{OH}\right]_{n}$, the calculated $\mathrm{C}$ content in the formula is $12.9 \%$ (as $\mathrm{C}$ ), which is also close to our measured $\mathrm{C}$ value for the composite ( $11.6 \%$ as $\mathrm{C}$ ), suggesting that the formula above is valid for the CMC-nHA composite, and that one mole of hydroxyapatite is bound by each mole of the CMC unit.
Promoting soybean growth and yield by nHA application. In the greenhouse, all the soybean plants matured (reached maximum heights) in $\sim 12$ weeks (Fig. 5). The maximum height of the plants under nHA treatment was on average $121 \mathrm{~cm}, \sim 30 \%$ higher than that of $93 \mathrm{~cm}$ under regular $\mathrm{P}$ fertilizer $\left(\mathrm{Ca}\left(\mathrm{H}_{2} \mathrm{PO}_{4}\right)_{2}\right)$ treatment. In comparison, control soybeans growing under tap water (no fertilizer application) and regular non-P fertilizer treatments, were much shorter with average mature heights of 59 and $63 \mathrm{~cm}$, respectively (Figs. 5 and 6). Linear fitting these growth rate curves in the first 12week period in Fig. 5 indicate the average growth rate of $11.4 \mathrm{~cm}$ week ${ }^{-1}$ for soybeans under nHA, and $8.6 \mathrm{~cm}$ week $^{-1}$ for regular $\mathrm{P}$ treatment in first 12 weeks, compared with the growth rates for controls of 5.1 and $4.8 \mathrm{~cm}^{\text {week }^{-1}}$, respectively. There was slight increase in soybean growth when the plants were treated with non$\mathrm{P}$ fertilizer $(\mathrm{N}$ and $\mathrm{K})$ instead of mere tap water, rather poor growth state was observed for these two control treatments (Fig. 6). The observation suggests that $\mathrm{N}$ is not a limiting nutrient for soybean due to the fact that a legume species could avail $\mathrm{N}$ through the symbiotic fixation process. Thus, $\mathrm{P}$ becomes the limiting and indispensable nutrient for healthy growth of soybean and other legumes, depending merely on the outer inputs. This also explains our observations where soybean growth rate increased by 1.5 folds when regular $P$ fertilizer was applied and healthy growth of the plants exhibited (Figs. 5 and 6). Interestingly, nHA application enhanced soybean growth even more than did the regular $\mathrm{P}$ addition (Figs. 5 and 6), which is also supported by the highest dry biomass (aboveground and underground) and the soybean seed yield under nHA treatment (Fig. 7). For instance, the average dry above-ground biomass was $13 \mathrm{~g}$ per plant under nHA treatment compared with $11 \mathrm{~g}$ for the regular P fertilizer application. In comparison, less than 2 g per plant biomass were harvested in cases without $\mathrm{P}$ application (controls). Similarly, below-ground biomass was the highest under nHA treatment of 80.9 g per plant, compared with 57.2 g per plant

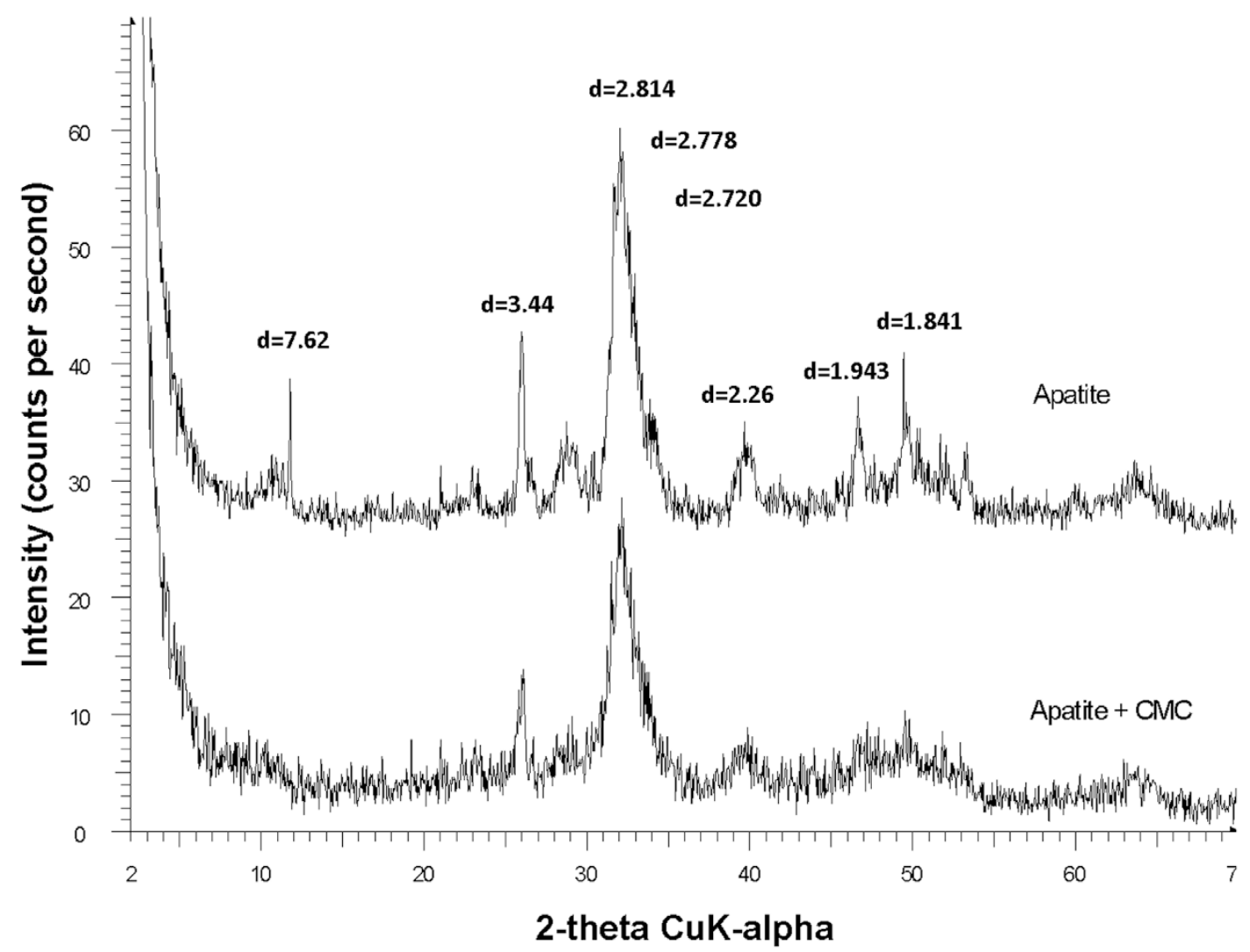

Figure $4 \mid$ X-ray diffraction patterns of hydroxyapatite precipitate and CMC-stablized nanoparticles. 


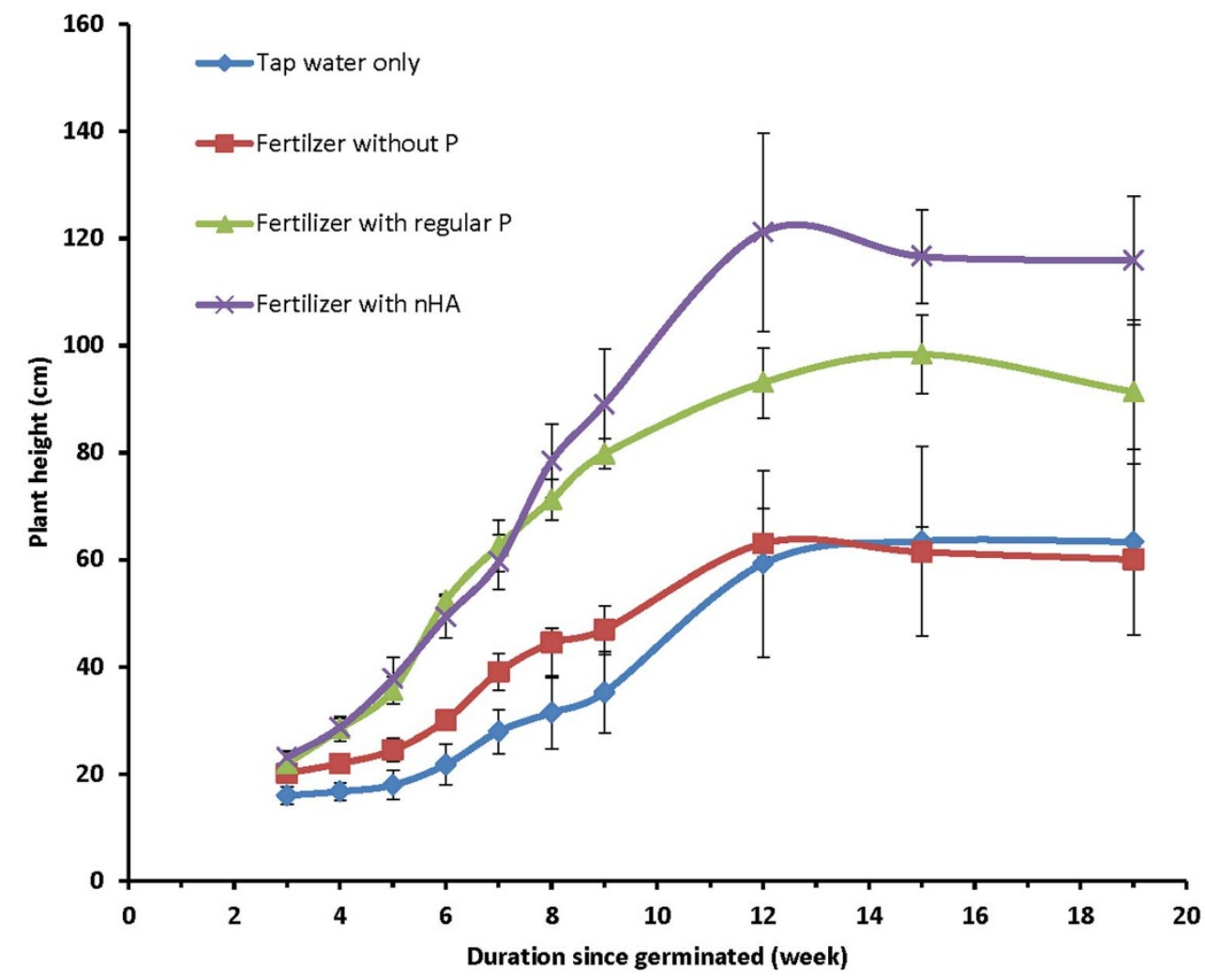

Figure $5 \mid$ Growth of soybean plants under different treatments. Error bars: standard deviations, $\mathrm{N}=15$.

for the regular $\mathrm{P}$ application and less than $2 \mathrm{~g}$ dry roots harvested from soybean without $\mathrm{P}$ additions. More importantly, nHA application produced $5.9 \mathrm{~g}$ soybean seeds per plant, compared with about $4.9 \mathrm{~g}$ per plant under regular $\mathrm{P}$ treatment, and merely 1.1 and $0.6 \mathrm{~g}$ soybean per plant respectively for the controls without $\mathrm{P}$ application. Thus, the $\sim 20$-week-long greenhouse study indicated that nHA application as a new type of $\mathrm{P}$ fertilizer increased rate of soybean growth, biomass productions, and the seed yield in an inert growing media compared to these under regular $\mathrm{P}$ treatment. This is the first report on synthesis and application of $\mathrm{nHA}$ as nano $\mathrm{P}$ fertilizer for increasing soybean yields. This experiment exhibited

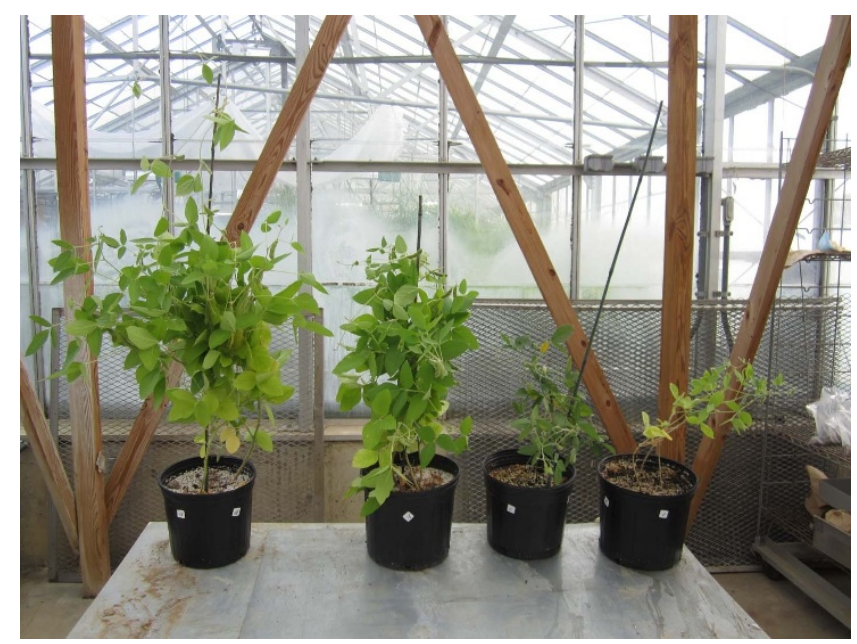

Figure $6 \mid$ Growth of soybean plants in the $15^{\text {th }}$ week after germination under different treatments. From left to right: treated with fertilizer and nano-sized hydroxyapatite (nHA), treated with fertilizer and regular $\mathrm{P}$, treated with fertilizer without $\mathrm{P}$, and treated with tap water only. that HA nanoparticles could be used as an effective $\mathrm{P}$ nutrient source as traditional soluble P fertilizers and that plants could take up $\mathrm{P}$ nutrients in nanoparticle formulation. Yet, more systematic research is needed to elucidate the mechanisms of plants taking up nHA as nutrient sources and the reasons why nHA performed better over soluble $\mathrm{P}$ fertilizer in enhancing soybean growth and seed yield. It is likely that the retention time of nHA was longer in the porous medium than that of the soluble phosphate, and thus the former had supplied more $\mathrm{P}$ to the plants than the latter. There might be two reasons for the difference in $\mathrm{P}$ retention time in the medium: (1). Soluble phosphates are more easily removed from the solution phase through precipitation when solution chemistry changes $(\mathrm{pH}$ increased or more cations introduced) or being absorbed by iron/ manganese minerals or other clay minerals ${ }^{13}$ while $\mathrm{nHA}$ may remain relatively stable in the suspension and be affected less by the solution $\mathrm{pH}$, co-existing ions, or solids. (2). The aqueous solution containing soluble $\mathrm{P}$ may leach out of the soil column faster than the nHA solution because the latter contained the macromolecular CMC and had higher viscosity. Thus, there was much more $\mathrm{P}$ remaining in the growing medium for plant roots to absorb in the case of nHA. Additional studies are under way to confirm those hypotheses. An assessment of nHA toxicity by lettuce seed germination test indicated that nHA did not exhibit any acute toxic or inhibitory effect on the germination and that applications of engineered nHA in the field should be safe to the environment and the ecosystem (see supplemental online material SOM-1).

\section{Conclusions and further research needs}

This may be the first study reporting the impact of synthesized nanosized hydroxyapatite (nHA) as a new class of $\mathrm{P}$ fertilizer to enhance the growth and yield of soybean through a greenhouse study. TEM images showed that the particles were in spherical shape with diameters of $15.8 \pm 7.4 \mathrm{~nm}$. The XRD confirmed the nanoparticles were pure hydroxyapatite $\left(\mathrm{Ca}_{5}\left(\mathrm{PO}_{4}\right)_{3} \mathrm{OH}\right)$. The 20 -week-long greenhouse test in an inert growing medium showed that application of $\mathrm{nHA}$ as a 

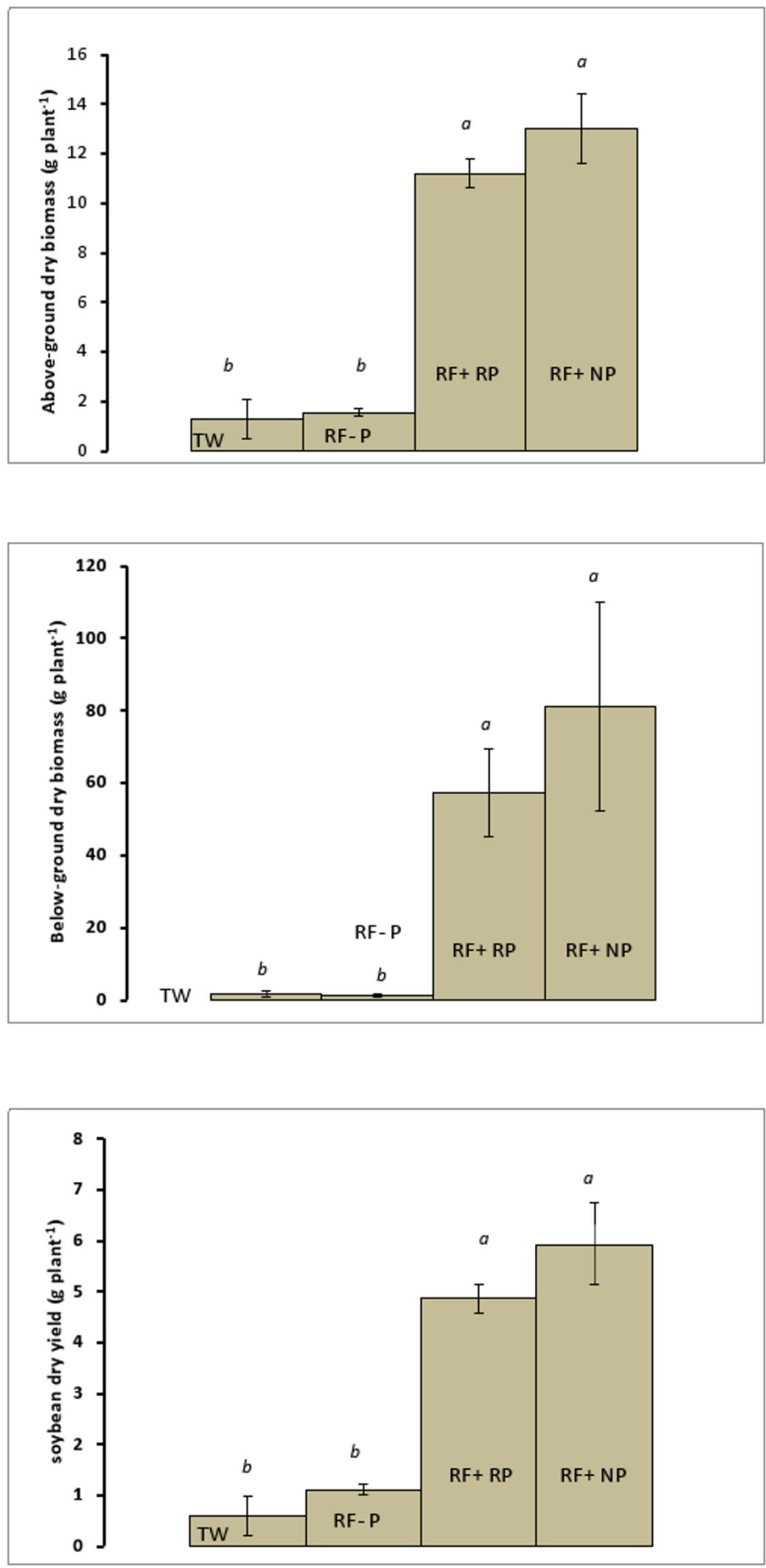

Figure 7 | Effects of nano-sized hydroxyapatite (nHA) on above-ground biomass (top), below-ground biomass (middle), and yield of soybeans (bottom). TW: soybeans treated by tap water; F-P: soybeans treated with fertilizer without P; F + RP: soybeans treated by fertilizer with regular P; and F + nHA: soybeans treated with nano-sized hydroxyapatite (nHA). Error bars: standard deviation, $\mathrm{N}=15$. 
Table 1 | Compositions of the synthetic fertilizers applied the soybeans during the greenhouse test

\begin{tabular}{|c|c|c|c|c|}
\hline Fertilizing schemes (treatment) & $\begin{array}{l}\text { Added nutrients }\left(\mathrm{mg} \mathrm{L}^{-1}\right) \\
\text { other than } \mathrm{P}\end{array}$ & $P$ nutrient $\left(\mathrm{mg} \mathrm{L}^{-1}\right)$ & $\begin{array}{l}\text { Amount and } \\
\text { frequency applied }\end{array}$ & $\begin{array}{l}\text { Number of containers } \\
\text { served }\end{array}$ \\
\hline Tap water & 0 & 0 & \multirow{3}{*}{$\begin{array}{l}1 \mathrm{~L} \text { per pot, weekly, } \\
\text { applied directly on } \\
\text { the medium surface }\end{array}$} & 5 \\
\hline Synthetic fertilizer solution with regular $P$ & \multirow{2}{*}{$\begin{array}{l}\mathrm{NH}_{4}-\mathrm{N}(39.9), \mathrm{NO}_{3}-\mathrm{N} \\
(60.1), \mathrm{K}(83.0), \mathrm{Mg}(0.8), \\
\mathrm{B}(0.1), \mathrm{Cu}(0.05), \mathrm{Fe}(0.5), \\
\mathrm{Mn}(0.28), \mathrm{Mo}(0.05) \\
\mathrm{Zn}(0.08)\end{array}$} & $\mathrm{Ca}\left(\mathrm{H}_{2} \mathrm{PO}_{4}\right)_{2}(21.8$ as $\mathrm{P})$ & & 5 \\
\hline $\begin{array}{l}\text { Synthetic fertilizer solution with nano } \\
\text { hydroxyapatite (nHA) }\end{array}$ & & $\mathrm{nHA}(21.8$ as $\mathrm{P})$ & & 5 \\
\hline
\end{tabular}

P source promoted more soybean growth at a rate of $11.4 \mathrm{~cm} \mathrm{week}^{-1}$, a $32.6 \%$ higher than that $\left(8.6 \mathrm{~cm} \mathrm{week}^{-1}\right)$ of soybeans growing under regular P fertilizer treatment. Moreover, nHA gave higher biomass production (a $18.2 \%$ increase in above-ground biomass and a $41.2 \%$ in below-ground biomass) and the yield (a 20.4\% increase) in compared with those under regular $P$ treatment. This research indicated that $n \mathrm{HA}$ could be used as a P fertilizer in enhancing crops' yields and biomass production. More research is needed to systematically elucidate the interaction of nHA with plants and soil. Field studies also needed to confirm the fertilizing effect of nHA on various plants and in various soil environments. The eutrophication potential of nHA needs to be specially addressed.

\section{Methods}

All chemicals used in this study were of analytical or higher grade. The sodium form of carboxymethyl cellulose ( $\mathrm{NaCMC}$, or $\left[\mathrm{C}_{6} \mathrm{H}_{7} \mathrm{O}_{2}(\mathrm{OH})_{2} \mathrm{CH}_{2} \mathrm{COONa}\right] \mathrm{n}$, molecular weight $\sim 90,000$ ) was purchased from Acros Organics (Morris Plains, NJ, USA). All other chemicals were purchased from Fisher Scientific (Pittsburgh, PA, USA). All solutions were prepared with deionized $(\mathrm{DI})$ water $(18 \mathrm{M} \Omega \mathrm{cm})$ from a Milli- $\mathrm{Q}^{\mathrm{TM}}$ Water System.

Preparation and characterization of the CMC-stabilized apatite nanoparticles. CMC, $\mathrm{PO}_{4}{ }^{3-}$, and $\mathrm{Ca}^{2+}$ solutions were prepared separately at certain concentrations using $\mathrm{NaCMC}, \mathrm{H}_{3} \mathrm{PO}_{4}$ and $\mathrm{Ca}(\mathrm{OH})_{2}$ in DI water. The nanoparticle preparation was carried out under normal laboratory conditions, where $25 \mathrm{~mL}$ of the $\mathrm{Ca}^{2+}$ solution was dropwise added to $50 \mathrm{~mL}$ of CMC solution under constantly mixing. After the mixture was stirred for $\sim 12 \mathrm{~h}, 25 \mathrm{~mL}$ of the phosphate solution was dropwise added to the mixture, also under constantly stirring. The molar ratio of $\mathrm{Ca}^{2+}$ to $\mathrm{PO}_{4}{ }^{3-}$ was $5: 3$ in accord with the stoichiometry of hydroxyapatite $\left(\mathrm{Ca}_{5}\left(\mathrm{PO}_{4}\right)_{3} \mathrm{OH}\right)$.

For TEM imaging, a drop of the apatite nanoparticle suspension was placed on a carbon-coated copper grid and then dried for $12 \mathrm{~h}$. The dried grid was then placed under a JEM-200CX TEM (JEOL, Japan). The images were taken at an acceleration voltage of $120 \mathrm{kV}$. Mineral phase identification was carried out by X-ray powder diffraction using a Scintag PAD-V diffractometer system (Scintag, USA) with $\mathrm{Cu} \mathrm{K} \alpha$ radiation $(\lambda=1.5406 \AA)$. Total carbon was analyzed following the Dumas method with a LECO CN-2000 combustion unit (LECO, USA) at $1050^{\circ} \mathrm{C}$. The nHA solid was obtained by centrifuging the solution at $4000 \mathrm{~g}$ for $96 \mathrm{hrs}(4 \mathrm{~d}$ ) (AccuSpin 3R, Fisher Scientific, Germany). The precipitate was rinsed several times with DI water after the supernatant was decanted. Air-dried precipitate was then ground into fine powder and stored for subsequent XRD and total C analyses.

Greenhouse test. Growth and yield of soybean are very sensitive to nutrient $\mathrm{P}^{13}$. Thus, soybean (Dennison) was selected in this greenhouse study to evaluate the fertilizing effect of nHA on a life cycle basis and compare with that of a regular P fertilizer $\left(\mathrm{Ca}\left(\mathrm{H}_{2} \mathrm{PO}_{4}\right)_{2}\right)$. An inert growing medium comprising of $50 \%$ peat moss (Fafard Inc., $\mathrm{MA}$ ) and $50 \%$ perlite (PVP Industries Inc., $\mathrm{OH}$ ) was used to avoid the possible interferences from the complicated soil components. Five soybean seeds were sowed in each 5-gallon plastic containers (plant pots) filled with the mixture in early April, 2013. Four fertilizing schemes (treatments) were used in this study and each treatment applied to 5 containers $(5$ replicates $\times 4$ treatments $=20$ containers in total). These treatments included tap water only, synthetic fertilizer without $\mathrm{P}$ synthetic fertilizer with regular $\mathrm{P}$, and synthetic fertilizer with nHA. The compositions of the synthetic fertilizers $\left(100 \mathrm{mg} \mathrm{L}^{-1} \mathrm{~N}\right)$ in this study followed those of a commercial fertilizer (20-10-20 Peat-Lite Special, the Scotts Company, OH) but prepared with pure chemicals in tap water (Table 1). Regular $\mathrm{P}\left(\mathrm{Ca}\left(\mathrm{H}_{2} \mathrm{PO}_{4}\right)_{2}\right)$ solution and nHAP were added respectively at the same amount (as P) for the latter two treatments. Fertilizer solutions were applied weekly to each container at $1 \mathrm{~L}$ solution per pot. The fertilizing started when the germinated soybeans were about $5 \mathrm{~cm}$ high in mid-April and stopped when the soybean pods looked full in earlier October. Besides, tap water applied as irrigation water when needed at $1 \mathrm{~L}$ per pot each time. Heights of the plants were measured using a ruler (the smallest unit: $\mathrm{mm}$ ) on roughly weekly basis for growth rate estimates. The five germinated seedlings were removed to 3 plants per pot after two month in early June. The soybeans were harvested by cut from the medium surface when about $80 \%$ of the whole plant turned brown. The above-ground biomass and soybean seeds were weighted after the plants were dried in an oven at $50^{\circ} \mathrm{C}$ for $7 \mathrm{~d}$ (dry weight). The growing medium was washed off from the roots and dry weight of the roots was taken as below-ground biomass. Those weights were applied to estimate the soybean biomass and seed yields.

All data were statistically analyzed by computing the one-way ANOVA using Minitab 16.1.1 (LEAD Technologies, Inc.). Treatment differences were assessed at $\mathrm{p}<0.05$.

1. Childers, D. L., Corman, J., Edwards, M. \& Elser, J. J. Sustainability challenges of phosphorus and food: solutions from closing the human phosphorus cycle. Bioscience 61, 117-124 (2011).

2. Correll, D. L. The role of phosphorous in the eutrophication of receiving waters: A review. J. Environ. Qual. 27, 261-266 (1998).

3. Daniel, T. C., Sharpley, A. N. \& Lemunyon, J. L. Agricultural phosphorus and eutrophication: A symposium overview. J. Environ. Qual. 27, 251-257 (1998).

4. Carpenter, S. R. Eutrophication of aquatic ecosystems: Biostability and soil phosphorus. Proc. Natl. Acad. Sci. USA 102, 9999-10001 (2005).

5. Carpenter, S. R. Phosphorus control is critical to mitigating eutrophication. Proc. Natl. Acad. Sci. USA 105, 11039-11040 (2008).

6. Conley, D. J. et al. Controlling eutrophication: nitrogen and phosphorus. Science 323, 1014-1015 (2009).

7. Litke, D. W. Review of phosphorus control measures in the United States and their effects on water quality. U.S. Geological Survey Water-Resources Investigations Report 99-4007 (1999). http://pubs.usgs.gov/wri/wri994007/pdf/wri99-4007.pdf. Date of access: 10/06/2013.

8. Hoffmann, C. C. et al. Phosphorus retention in riparian buffers: review of their efficiency. J. Environ. Qual. 38, 1942-1955 (2009).

9. Kronvang, B. et al. Phosphorus losses from agricultural areas in river basins: effects and uncertainties of targeted mitigation measures. J. Environ. Qual. 34, 2129-2144 (2005).

10. Vadas, P. A., Good, L. W., Moore, P. A. Jr. \& Widman, N. Estimating phosphorus loss in runoff from manure and fertilizer for a phosphorus loss quantification tool. J. Environ. Qual. 38, 1645-53 (2009).

11. De-Bashana, L. E. \& Bashana, Y. Recent advances in removing phosphorus from wastewater and its future use as fertilizer (1997-2003). Water Res. 38, 4222-4246 (2004).

12. Buda, A. R., Koopmans, G. F., Bryant, R. B. \& Chardon, W. J. Emerging technologies for removing nonpoint phosphorus from surface water and groundwater: introduction. J. Environ. Qual. 41, 621-627 (2012).

13. Fageria, N. K. The Use of Nutrients in Crop Plants. (CPC Press, Boca Raton, 2009). 14. Reynolds, C. S. \& Davies, P. S. Sources and bioavailability of phosphorus fractions in freshwaters: a British perspective. Biol. Rev. 76, 27-64 (2001).

\section{Author contributions}

R. Lal and R. Liu planned the experiment. R. Liu conducted the experiment and wrote the manuscript. R. Lal revised the manuscript. Both authors reviewed the manuscript.

\section{Additional information}

Supplementary information accompanies this paper at http://www.nature.com/ scientificreports

Competing financial interests: The authors declare no competing financial interests.

How to cite this article: Liu, R.Q. \& Lal, R. Synthetic apatite nanoparticles as a phosphorus fertilizer for soybean (Glycine max). Sci. Rep. 4, 5686; DOI:10.1038/srep05686 (2014).

This work is licensed under a Creative Commons Attribution-NonCommercialNoDerivs 4.0 International License. The images or other third party material in this article are included in the article's Creative Commons license, unless indicated otherwise in the credit line; if the material is not included under the Creative Commons license, users will need to obtain permission from the license holder in order to reproduce the material. To view a copy of this license, visit http:// creativecommons.org/licenses/by-nc-nd/4.0/ 